\title{
On the Causes of Superiority Effects in Spanish: Preliminary Results and Prospects*
}

\author{
Luis Vicente
}

Universität Potsdam. Department Linguistik

vicente@uni-potsdam.de

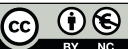

Received: July 10, 2013

Accepted: September 5, 2013

\begin{abstract}
This article reports the results of a series of experiments (acceptability rating tasks) on a group of speakers of Andalusian Spanish. The main result is that, contrary to previous claims in the literature (cf. Jaeggli 1982 et seq), Spanish does exhibit a Superiority effect in multiple wh- questions. However, this effect can be subsumed under a generalized mild penalty on object wh- fronting, also not described in previous literature. Consequently, this article provides novel support for approaches to Superiority effects where locality violations play at most a minor role.
\end{abstract}

Keywords: superiority; object fronting; wh- questions; relative clauses; Spanish.

\section{Table of Contents}
1. Introduction
4. Conclusions and outlook
2. Participants and materials
References

3. Results and discussion

\section{Introduction}

The classic definition of Superiority states that, in a multiple wh- question, the wh- phrase that undergoes fronting is the structurally highest one -i.e., a low wh- phrase cannot skip over a higher one-. Thus, (1a) is a well-formed multiple question, but (1b) is not.

* This article would not have been possible without the assistance of Javier Martín González (who distributed the questionnaires among his students), Sebastian Grüner (who carefully tabulated many pages of results), and Jana Häussler and Shravan Vasishth (who were always read for discussions about statistical analysis). All remaining errors are nobody's fault but mine. 
(1) a. Who read what?

b. *What did who read?

Given that that Superiority effects are usually dependent on the relative structural height of the wh- phrases in question, and given that this relation can be equated with the asymmetric c-command relation, many approaches have attempted to reduce Superiority to general locality restrictions (e.g., Relativized Minimality, the Minimal Link Condition, and other similar formulations). For example, Chomsky (1995) subsumes Superiority effects under the more general Attract Closest condition, which states that $« \alpha$ can raise to target $K$ only if there is no legitimate operation Move $\beta$ targeting $K$, where $\beta$ is closer to $K$ », where closeness is defined in the usual c-command terms. While this approach is undoubtedly elegant and simple, it has to face two separate problems. The first one is the existence of missing Superiority effects i.e., environments where expected Superiority effects fail to appear. For example, Pesetsky (1987) already observed that Superiority effects in English disappear if the wh- words are D-linked: compare (1b) to (2b).

(2) a. Which student read which book?

b. Which book did which student read?

Similarly, it has also been observed that other languages have a distribution of Superiority effects that doesn't match the one observed in English. For example, Fanselow (2004) and Fanselow and Féry (2008) show that German exhibits Superiority effects with non-D-linked wh- words only if the two wh- words are not clause mates. ${ }^{1}$ Similar effects obtain in a number of other languages.

(3) a. Wer hat was gesagt?

who has what said

b. Was hat wer gesagt?

what has who said

'Who has said what'

c. Wem hat er $t_{w e m}$ empfohlen, [was zur Safari mitzubringen]? who has he recommended what to.the Safari bring 'Who has he recommended to bring what for the Safari?'

d. \#Was hat er wem empfohlen, $\left[t_{\text {was }}\right.$ zur Safari mitzubringen]? what has he who recommended to.the Safari bring 'Who has he recommended to bring what for the Safari?'

The second problem, the existence of unexpected Superiority violations, is the counterpart of the missing Superiority effects problem. As an illustration, consider

1. Featherstone (2005) disputes the acceptability of (3b). See, however, Fanselow et al (2011) for an explicit discussion of this issue. 
Aoun and Li's (2003) discussion of Lebanese Arabic, who argue that standard locality-based approaches cannot account for the unacceptability of examples like (4). Here, the base positions of the two wh- words don't c-command each other. On the assumption that asymmetric c-command is a necessary condition for Superiority effects, neither wh- word ought to induce a Superiority effect on wh- fronting of the other. Additionally, note that -ayya walad 'which boy' is contained inside an adjunct island. On the assumption that Superiority effects require both wh- words to be eligible for wh- fronting, -ayya walad should not block fronting of miin. ${ }^{2}$

*Miin fakkar-to la-inno 1-m? Pik?t ma? -ayya walad -? who thought.2PL because the.teacher.FEM spoke with which boy that 1-mudiira Pa-t-?-a-o? the.principal.FEM will.3.FEM.SG.expel.him.

'Who did you think that the teacher spoke with which boy because the principal will expel (him)?'

(5) Schematic representation of (4)

$\left[{ }_{\mathrm{CP}} \mathrm{who}_{\mathrm{i}}\left[{ }_{\mathrm{IP}} \ldots\right.\right.$ [island $\ldots$ which boy $\left.\left.\ldots . . . . \operatorname{him}_{\mathrm{i}}\right]\right]$

When it comes to the analysis of data like these, one can distinguish two different lines of attack in the literature. One of them attempts to preserve the traditional intuition that locality is the main predictor of acceptability, and postulates various amendments to the standard theory of locality in order to account for the offending sentences. For example, Aoun and Li (2003) propose to augment the standard definition of locality with a Minimal Match Condition (effectively, an additional locality constraint) in order to account for unexpected Superiority effects like (4). Similarly, Fanselow (1997) and Müller (2004) both argue (although with different technical implementations) that the lack of Superiority effects in (3b) reflects the fact that German objects can routinely scramble to the left of subjects. This possibility allows wh- movement of was 'what' to start from the scrambled position, so that no illegal wh- crossing over wer 'who' obtains. Finally, Pesetsky (1987, 2000) argues that the lack of Superiority effects with D-linked wh- phrases (2b) is a consequence of the fact that they do not actually move to Spec, CP - they are simply base-generated there and then associated to their variables through unselective binding-.

In opposition to this trend, the second major approach to Superiority effects downplays the importance of locality factors, and proposes instead that much, if not all, of the observed deviance stems from an independent set of factors. For example, Chomsky (2005), reversing his earlier approach to this issue, writes that «standard

2. Notably, similar configurations in English are judged as acceptable in the literature. Consider (i), from Fiengo et al (1988). As in (4), the base positions of the wh- words don't c-command each other, and where is ineligible for movement by virtue of being contained in a subject island. See Fitzpatrick (2002) for additional discussion.

(i) What did [people from where] try to buy $t_{w h a t}$ ? 
efforts to account for Superiority effects in terms of locality do not apply, at least in an obvious way», although he doesn't elaborate on this idea any further. More specific is the study of Fanselow and Féry (2008), who argue that the unacceptability of (3d) is not due to a low wh- word crossing over a higher one, but rather to the general badness of long-distance wh- movement in German (see Fanselow 2004, Haider 2004, and Fanselow et al 2001 for additional arguments to this effect).

The goal of this paper is to provide additional support for the latter approach by examining Superiority effects in Spanish. The argumentation is based on the results of three experiments (acceptability rating tasks), each targeting a different operator fronting construction in Spanish, viz., single questions, multiple questions, and relative clauses. I am aware that some readers might wonder about the adequacy of using Spanish to investigate this particular topic, given that Spanish is one of the languages where Superiority effects are claimed to be absent. For example, Ordóñez (1997: 53), citing Jaeggli (1982), provides the following pair of sentences, with judgments as quoted here, and with the explicit comment that «a Superiority effect does not arise between a wh- word in Spec,CP and the postverbal wh- word».

(6) a. ¿Quién compró qué? who bought what

b. ¿Qué compró quién? what bought who

However, Experiment B (section 3.2) shows that this judgment is inaccurate. The mean rating of sentences comparable to (6b) is somewhat lower than that of sentences comparable to (6a), and the difference turns out to be of high statistical significance. Thus, it is necessary to accept that (at least for speakers of the particular dialect sampled here), fronting of a low wh- word across a higher one incurs a non-trivial penalty. The relevant question is whether this penalty is the reflection of a Superiority effect as traditionally understood - i.e., a violation of Relativized Minimality, Attract Closest, or some equivalent locality condition on movement-. As we will see, the three experiments I present suggest that this question should be answered in the negative: fronting of a wh- object correlates a mild penalty irrespective of whether it crosses over a wh- subject or not, and this can account for at least a significant part of the deviance of object-initial multiple wh- questions. Due to the limited scope of this study, it is not possible yet to totally exclude locality factors from consideration. However, the results I present here (to the extent that they can be replicated and extended in future studies) point towards an analysis of Superiority effects in Spanish where pure locality factors play at most a marginal role as predictors of acceptability.

\section{Participants and materials}

The participants in the experiments were 64 undergraduate students from the University of Seville, all of them native speakers of Spanish (13 male, median age 24). With the exception of only 4 participants, all of them reported some non- 
native knowledge of at least one foreign language — mainly English (45), French (26), and/or Italian (13) — Within the confines of this study, it is not possible to determine to what extent knowledge of a foreign language influences judgments, given the lack of a strictly monolingual group of sufficient size to use as a comparison baseline.

The study, which was carried out in April 2013, consisted on an acceptability rating task over a 7-point scale (with 7 corresponding to total acceptability) using paper questionnaires. The experimental items are a close replication of those used in an ongoing study by Gisbert Fanselow and Jana Häussler on Superiority effects in German, English, and Czech. The items comprise five separate experiments (see below for details), and they were constructed in such a way that the items from any four experiments could serve as fillers for the fifth. In addition, there were 12 independent fillers not related to any of the subexperiments. 12 separate questionnaires were created (96 items per questionnaire, including fillers) using a set of custom Python scripts that ensured that the experimental items were properly distributed across questionnaires. Specifically, this script ensured that, within each questionnaire, (i) no items from the same experiment appeared directly adjacent to each other, and (ii) once an item from a certain experiment was encountered, the next item from the same experiment would belong to a different condition. Interested readers can download a compressed folder with all the experimental materials (list of items, randomization scripts, questionnaires, and .csv tables of the results) from http://www.luisvicente.net/supplemental_materials/superiority.tar.gz.

The discussion in this article will be limited to results of three of these five experiments. One of the experiments that I don't discuss tested the acceptability of wh- extraction out of complement clauses and relative clauses, yielding the rather unsurprising result that extraction out of relative clauses is severely degraded compared to extraction out of complement clauses. The other experiment was meant to test whether the absence/presence of a c-command relation between the base positions of multiple wh- words has an effect on Superiority effects, but these data had to be discarded due to a generalized design flaw in the experimental items.

\section{Results and discussion}

All results were analyzed using linear mixed effects models, with both Subjects and Items as random effects (the fixed effects vary across experiments and will be detailed in the following subsections). The goal of this approach is to avoid the language-as-a-fixed-effect fallacy (Clark 1973) as well as certain limitations of carrying out separate by-subjects and by-items analyses (Raaijmakers 2003). Throughout this section, I present $p$-values (with $\alpha=.05$, as customary) estimated from Markov chain Monte Carlo (MCMC) sampling (cf. Baayen et al 2008 and references). To assess the validity of these analyses, I have also performed likelihood ratio tests comparing the models with fixed effects to null models with only the random effects. All the calculations have been done with the aid of the $\mathrm{R}$ statistical software (http://www.r-project.org) and specifically, the packages lme4 (Bates et al 2009) and languageR (Baayen 2009). 


\subsection{Experiment A: object vs. subject wh- fronting in single questions}

This experiment (items 30101 to 31202 in the item list) establishes a baseline by comparing the acceptability of single questions with a wh- subject vs. that of single questions with a wh- object. It consists of a single factor Fronted Argument, with levels subject and object. Twelve lexicalizations of this design were prepared, one of which is provided below for reference. In all the lexicalizations, simple whwords were employed (quién 'who' and qué 'what') and the non-wh- argument was a simple indefinite (alguien 'someone' and algo 'something'). Similarly, in all cases the subject was animate and the object was inanimate, and the rightmost constituent of the embedded clause was a time or place adverbial.

(7) Sample items
a. Carlos no nos dijo quién había comprado algo en la feria. Carlos not us told who had bought something in the fair [subject wh- fronting]

b. Carlos no nos dijo qué había comprado alguien en la feria. Carlos not us told what had bought someone in the fair [object wh-fronting]

The results are summarized in the plot and the table in Figure 1 below. A linear mixed effects model (with Subjects and Items as random effects and Fronted Argument as a fixed effect) reveals that the difference in means is highly significant $(p<.001)$. A likelihood ratio test against a null model also yielded a highly

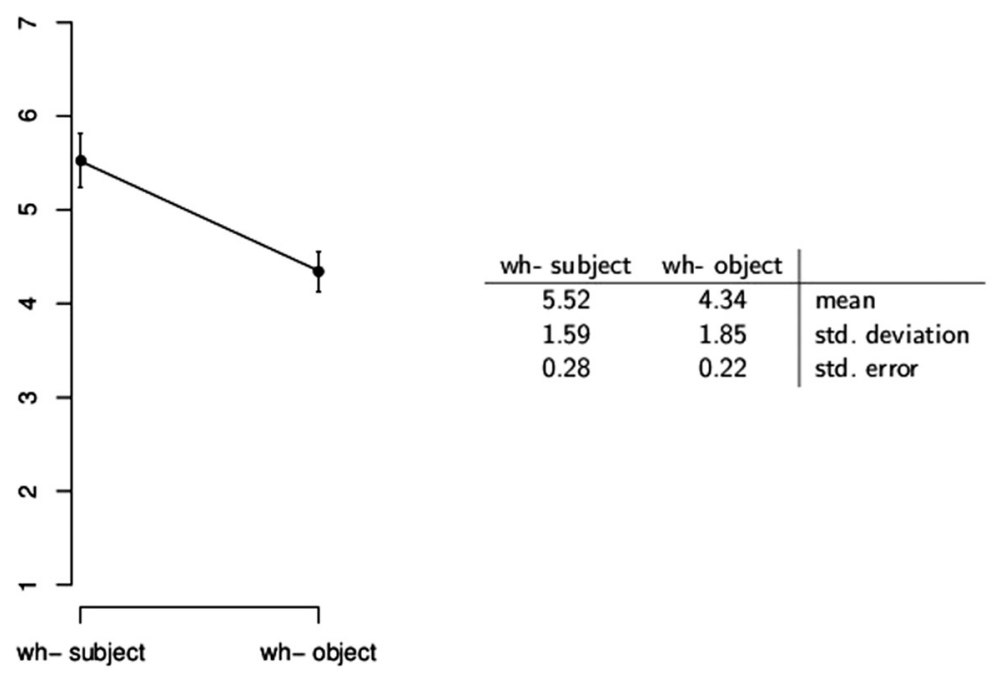

Figure 1. Results of Experiment A. 
significant result $(p<.001)$, supporting the conclusion that the fixed effect should be considered a predictor of acceptability.

This result (i.e., that object wh- fronting is degraded relative to subject whfronting, even in the absence of a Superiority configuration) is surprising because, to the extent of my knowledge, it has not been reported in previous literature on Spanish. However, this doesn't mean it is crosslinguistically unique. The ongoing study on Czech by Gisbert Fanselow and Jana Häussler, on which the present study is heavily based, reports an effect of a comparable magnitude (on separate bysubjects and by-items analyses, $\mathrm{F}_{1}=35.56, p<.001, \mathrm{~F}_{2}=26.77, p<.001$; see the examples below). However, they also report that this effect is absent in German and English. At present, I am not in a position to speculate why only some languages impose a mild penalty on object wh- fronting.

(8) Czech: significant effect of order

a. Domovník pozoroval, kdo ze zásob něco kradl. caretaker observed who PRT held something stolen 'The caretaker noticed who had stolen something'

[subject wh- question: mean rating 5.73]

b. Domovník pozoroval, co někdo kradl ze zásob. caretaker observed what someone stolen PRT held 'The caretaker noticed what someone had stolen'

[object wh- question: mean rating 4.84]

\subsection{Experiment B: interaction of animacy and order in multiple wh-questions}

The second experiment (items 10101 to 12004 in the item list) tracks the effects of object animacy in multiple questions with either subject or object wh- fronting. It consists of two factors: (i) Fronted Argument, with levels subject and object; and (ii) Object Animacy, with levels animate and inanimate. The addition of Object Animacy as a factor is motivated by the results of Fanselow et al (2011), who show that it does have an effect in German A-bar movement constructions (cf. the discussion in section 3.6). Twenty lexicalizations of a $2 \times 2$ design were prepared, one of which is provided here for reference. ${ }^{3}$

3. In this set of examples, the gloss DOM is the acronym of Differential Object Marker, required for human/ animate objects. This gloss reflects the consensus in the literature that, in this particular environment, $a$ is a genuine case marker, rather than a preposition (cf. Strotzer 1976, Suñer 1988, Cuervo 2003). 


\section{(9) Sample items}

a. Nadie sabía quién había votado a quién en las elecciones. nobody knew who had voted DOM who in the elections

[subject wh-fronting; animate object]

b. Nadie sabía quién había votado qué en las elecciones. nobody knew who had voted what in the elections [subject wh-fronting; inanimate object]

c. Nadie sabía a quién había votado quién en las elecciones. nobody knew DOM who had voted who in the elections [object wh-fronting; animate object]

d. Nadie sabía qué había votado quién en las elecciones. nobody knew what had voted who in the elections [object wh-fronting; inanimate object]

The results of the experiment are summarized in Figure 2. A linear mixed effects analysis reveals a highly significant main effect for the Fronted Argument factor $(p>.001)$ but not for the Object Animacy factor $(p=.60) .{ }^{4}$ Additionally, the Fronted Argument $\times$ Object Animacy interaction is also significant $(p<.001)$. A likelihood ratio test against a null model yields a significant result $(p<.001)$, supporting the conclusions of the linear mixed effects analysis.

\subsection{Comparison of experiments $A$ and $B$}

The most important conclusion of Experiment B is the significant main effect of the Fronted Argument factor, which reverses previous claims in the literature to the effect that Spanish lacks Superiority effects (cf. the discussion around example (6b) above). The issue I want to address now is whether this is a genuine Superiority effect in the traditional sense of the term (i.e., a violation of a locality condition on movement). Experiment A already showed that fronting of a wh- object in single questions is already associated to a significant penalty on its own. How much of the deviance of examples like (9c) and (9d) can be attributed to this penalty? To put it in a different way, once we factor in the generalized badness of object wh- fronting, is there any room left for locality factors in the analysis of (9c) and (9d)?

Answering this question requires a comparison of Experiments $\mathrm{A}$ and $\mathrm{B}$, and this is complicated by the fact that the two experiments have different designs - specifically, Experiment A features the single factor Fronted Argument, whereas Experiment B crosses this factor with Object Animacy to yield a $2 \times 2$ designThis asymmetry can be partly corrected by capitalizing on the fact that all the

4. Note, however, that subject initial examples with an inanimate object receive a lower mean rating than their counterparts with an animate object. The ongoing study by Gisbert Fanselow and Jana Häussler reports a similar asymmetry in Czech, but not in English or German. As above, I am not in a position to speculate why this is the case in some languages but not others. 


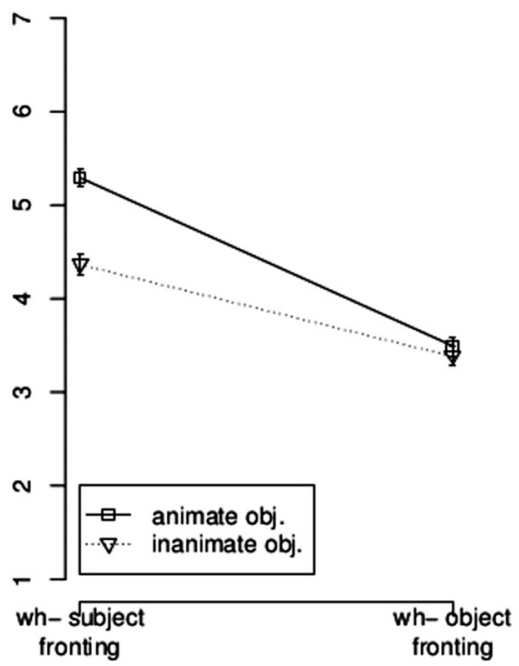

\begin{tabular}{rr|cc|c} 
& & animate obj & inanimate obj & marginal \\
\hline \multirow{3}{*}{ subj. fronting } & mean & 5.29 & 4.37 & 4.88 \\
& std dev & 1.85 & 1.92 & 1.94 \\
& std err & 0.10 & 0.11 & 0.10 \\
\hline \multirow{2}{*}{ obj. fronting } & mean & 3.49 & 3.39 & 3.44 \\
& std dev & 1.81 & 1.91 & 1.86 \\
& std err & 0.10 & 0.11 & 0.11 \\
\hline \multirow{2}{*}{ marginal } & mean & 4.49 & 3.88 & \\
& std dev & 2.04 & 1.97 & \\
& std err & 0.11 & 0.11 &
\end{tabular}

Figure 2. Results of Experiment B.

items in Experiment A feature an inanimate object. Therefore, it is possible to compare them against the items in Experiment B that also have an inanimate object. The resulting data frame crosses the Fronted Argument factor (levels subject and object) with the Question Type factor (levels multiple and single) to obtain a $2 \times 2$ design.

The results of the comparison are summarized in Figure 3. A linear mixed effects model (with Subjects and Items as random effects and Fronted Argument and Question Type as fixed effects) yields a significant main effect for both the Fronted Argument factor $(p<.001)$ and the Question Type factor $(p<.001)$, but not for the Fronted Argument $\times$ Question Type interaction $(p=.41)$. A likelihood ratio test against a null model yields a significant result $(p<.001)$, supporting the hypothesis that both fixed effects should be considered predictors of acceptability. 
The fact that the Fronted Argument factor yields a significant main effect is unsurprising, given that it already yields a main effect of a comparable magnitude in both Experiment A and Experiment B. The significant main effect of the Question Type factor indicates that multiple questions incur a penalty, whereas single questions do not. What is relevant for the purposes of this paper is the lack of an interaction effect. These results argue against an analysis of Superiority effects in Spanish based on locality factors (i.e., violations of the Minimal Link Condition, Relativized Minimality, or some equivalent locality constraint). Specifically, if this type of analysis were correct, we would expect the penalty associated to a locality violation to pile upon the penalty associated to wh- object fronting. That is, the difference in acceptability between the subject wh- fronting condition and the object wh- fronting condition should be larger in multiple questions than in single questions. Such an effect would show up in the plot in Figure 3 as clearly diverging

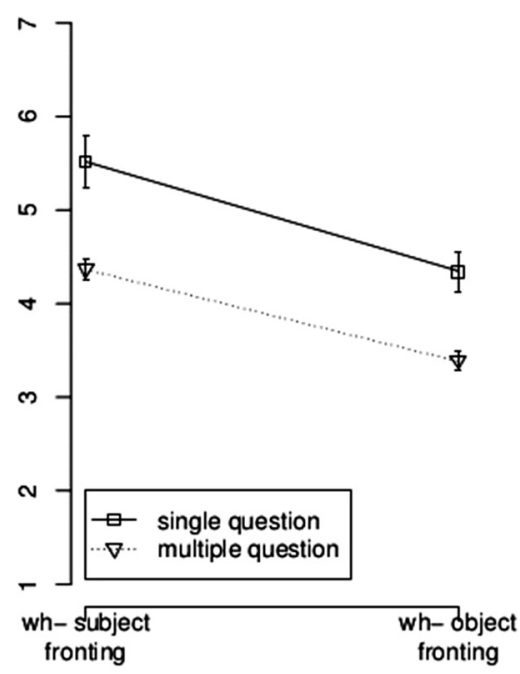

\begin{tabular}{rr|cc|c} 
& & single quest. & multiple quest. & marginal \\
\hline \multirow{3}{*}{ subj. fronting } & mean & 5.52 & 4.37 & 5.01 \\
& std dev & 1.59 & 1.92 & 1.83 \\
& std err & 0.28 & 0.11 & 0.07 \\
\hline \multirow{3}{*}{ obj. fronting } & mean & 4.34 & 3.39 & 3.44 \\
& std dev & 1.85 & 1.91 & 1.93 \\
& std err & 0.22 & 0.11 & 0.07 \\
\hline \multirow{2}{*}{ marginal } & mean & 4.93 & 3.88 & \\
& std dev & 1.82 & 1.97 & \\
& std err & 0.16 & 0.11 &
\end{tabular}

Figure 3. Comparison of Experiments $A$ and $B$. 
lines. In reality, as we have seen, this is not the case (cf. the nearly parallel lines in the plot). Rather, the data collected in these two experiments argue in favor of an approach in which the observed Superiority effect can be subsumed under the generalized deviance of object wh- fronting.

\subsection{Experiment $C$ : interaction of subject/object relativization with animacy}

The final experiment (items 20101 to 22004 in the item list) examines the interaction of two factors in relative clauses, namely, Relativized Argument (with levels subject and object) and Object Animacy (with levels animate and inanimate). The goal here is to determine whether the effects observed in Experiment A and Experiment B are exclusive to wh- questions or whether they generalize to other A-bar movement constructions - in this particular case, relative clauses-. As in Experiment B, twenty lexicalizations of a $2 \times 2$ design were prepared, one of which is provided below for reference.

(10) Sample items

a. El artículo hablaba sobre un reportero que había grabado a un the article talked about a reporter who had filmed DOM a terrorista en Irak. terrorist in Iraq

[subject relativization, animate object]

b. El artículo hablaba sobre un reportero que había grabado un the article talked about a reporter who had filmed a atentado en Irak.

bombing in Iraq

[subject relativization, inanimate object]

c. El artículo hablaba sobre un terrorista al que un reportero había the article talked about a terrorist DOM who a reporter had grabado en Irak.

filmed in Iraq

[object relativization, animate object]

d. El artículo hablaba sobre un atentado que un reportero había the article talked about a bombing which a reporter had grabado en Irak.

filmed in Iraq

[object relativization, inanimate object]

The experimental results are summarized in Figure 4 below. A simple visual inspection of the plot, which exhibits nearly horizontal lines with barely any separation, suggests that one is unlikely to find significant effects of any kind. A linear mixed effects model (with Subjects and Items as random effects, and Object Animacy and Relativized Argument as fixed effects) confirms this intuition, as there is no significant main effect for either the Object Animacy factor $(p=.42)$ 


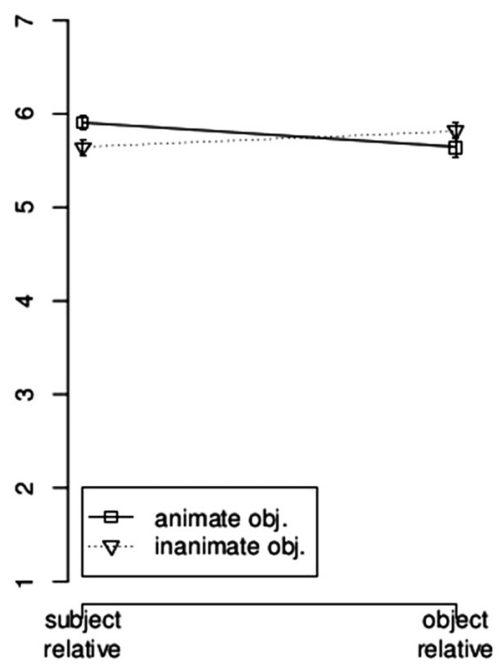

\begin{tabular}{rr|cc|c} 
& & animate obj. & inanimate obj. & marginal \\
\hline \multirow{2}{*}{ subject rel. } & std dev & 5.91 & 5.64 & 5.77 \\
& 1.43 & 1.83 & 1.66 \\
std err & 0.08 & 0.10 & 0.07 \\
\hline \multirow{2}{*}{ object relative } & mean & 5.68 & 5.82 & 5.77 \\
& std dev & 1.60 & 1.46 & 1.54 \\
marginal & std err & 0.08 & 0.08 & 0.06 \\
\hline & mean & 5.80 & 5.74 & \\
& std dev & 1.53 & 1.66 & \\
& std err & 0.06 & 0.07 &
\end{tabular}

Figure 4. Results of Experiment C.

or the Relativized Argument factor $(p=.31)$. The Object Animacy $\times$ Relativized Argument interaction also fails to reach significance $(p=.16)$. Furthermore, a likelihood ratio test against a null model also reveals a non-significant difference ( $p=.66$ ), further supporting the conclusion that neither Object Animacy nor Relativized Argument should be considered acceptability predictors with respect to this particular data set.

\subsection{Comparison of Experiment $C$ with Experiments $A$ and $B$}

Given the results of Experiments A and B, it is noteworthy that Experiment $\mathrm{C}$ doesn't yield any significant main effect or interaction effect. Consider, for illustration, a comparison of Experiment A against the items in Experiment $\mathrm{C}$ with an inanimate object. This comparison can be arranged in a $2 \times 2$ design with 
factors Fronted Argument (with levels subject and object) and Clause Type (with levels question and relative clause). The results are summarized in Figure 5 below. A linear mixed effects model (with Subjects and Items as random effects and Fronted Argument and Clause Type as fixed effects) reveals a significant main effect of the Fronted Argument factor $(p<.001)$ as well as of the Clause Type factor $(p<.001)$. The Fronted Argument $\times$ Clause Type interaction is also significant $(p<.001)$. Comparison against a null model also yields a significant result $(p<.001)$, supporting the conclusions of the linear mixed effects model.

The fact that object relativization doesn't receive the same penalty as object wh- fronting is somewhat surprising from a theoretical perspective, given that both relativization and wh- movement are cases of A-bar movement and share many syntactic and semantic properties. Regrettably, the question of why these two constructions differ in this particular way cannot be answered without further

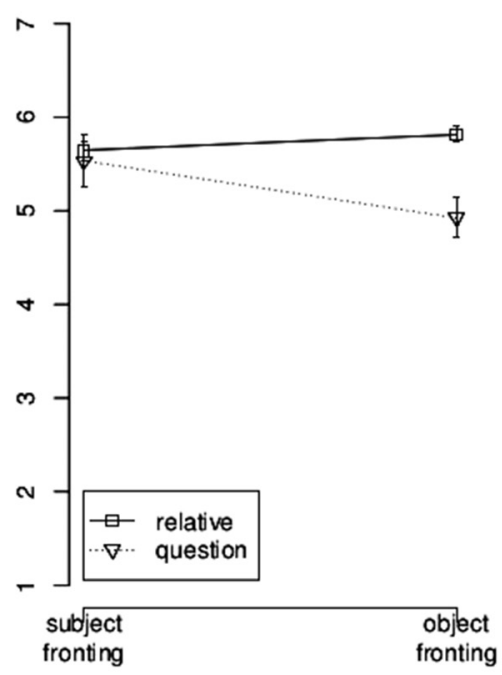

\begin{tabular}{rr|cc|c} 
& & question & relative & marginal \\
\hline \multirow{3}{*}{ subj. fronting } & mean & 5.52 & 5.64 & 5.58 \\
& std dev & 1.59 & 1.83 & 1.79 \\
& std err & 0.28 & 0.10 & 0.06 \\
\hline \multirow{3}{*}{ obj. fronting } & mean & 4.34 & 5.82 & 5.02 \\
& std dev & 1.85 & 1.46 & 1.84 \\
& std err & 0.22 & 0.08 & 0.07 \\
\hline \multirow{2}{*}{ marginal } & mean & 4.93 & 5.74 & \\
& std dev & 1.82 & 1.66 &
\end{tabular}

Figure 5. Comparison of Experiments $\mathrm{A}$ and $\mathrm{C}$. 
testing, and here there are two important factors to take into account. The first one concerns word order: as attentive readers might have noticed, all the wh- questions (both single and multiple) featuring object wh- fronting involve subject-verb inversion. This is a requirement for many dialects of Spanish, (cf. Baković 1998) and references), with lack of inversion typically resulting in unacceptability. Compare:

(11) a. Carlos no nos dijo qué había comprado alguien en la feria. Carlos not us told what had bought someone in the fair [subject-verb inversion]

b. *Carlos no nos dijo qué alguien había comprado en la feria. Carlos not us told what someone had bought in the fair [no subject-verb inversion]

In contrast, object relativization is more lenient and permits both subject-verb inversion and lack thereof (cf. the examples below).

(12) a. El artículo hablaba sobre un atentado que había grabado un the article talked about a bombing which had filmed a reportero en Irak. reporter in Iraq

\section{[subject-verb inversion]}

b. El artículo hablaba sobre un atentado que un reportero había the article talked about a bombing which a reporter had grabado en Irak.

filmed in Iraq

[no subject-verb inversion]

Furthermore, an anonymous reviewer of this paper points out that Southern Spain dialects don't require subject-verb inversion if the fronted wh-phrase is D-linked, offering (13) as an illustration. These patterns indicate that future investigations of this paradigm should incorporate Subject-Verb Inversion as an additional factor (with levels inversion and no inversion). ${ }^{5}$

(13) Carlos no sabía qué marca de manzanilla Juan había bebido en la feria.

Additionally, focus effects might arguably play a role too. As has been sometimes been noted in the literature, object focus fronting is more restricted in Spanish

5. The characterization of qué marca de manzanilla as D-linked comes from the reviewer. At present, I do not know if the relevant factor is D-linking or just the additional morphosyntactic complexity of the wh- phrase. Note also that (13) features the proper name Juan as the subject of the embedded clause, in contrast to the simple indefinite alguien 'someone' used in Experiments A and B. At present, I do not know if this is a significant factor. Similarly, the reviewer doesn't comment on the acceptability of (13) relative to a counterpart exhibiting subject-verb inversion. As mentioned above, further testing is required to determine if there is a significant difference. 
than it is in other languages. Specifically, Adli (2011) notes that, even among speakers that accept it, object focus fronting is significantly more degraded than the in situ alternative. Consider the following minimal pair as an illustration:

(14) a. [F El móvil] perdió Martín por casa.

the cell.phone lost Martín at home

[object focus fronting: mean rating, 61.8/100]

b. Martín perdió ${ }_{\mathrm{F}}$ el móvil] por casa.

Martín lost the cell.phone at home

[object focus in situ: mean rating, 74.6/100]

Wh- questions and sentences with foci are similar to each other, and different from relative clauses, in a non-trivial way: wh- questions and foci impose a specific focus-background partition on the sentence, but relative clauses do not. Therefore, it is conceivable that Spanish penalizes certain ways of articulating this partition - among them, those that involve fronting of an object focus or wh- wordIf further testing incorporating sentences with foci reveals a significant correlation in this respect, there will be a possibility to properly model the observed difference between object wh- fronting and object relativization.

\subsection{Effects of object animacy}

Experiments $\mathrm{B}$ and $\mathrm{C}$ have shown that the Object Animacy factor is not a good predictor of acceptability in Spanish - i.e., it doesn't give rise to a main effect in either relative clauses or multiple questions, and it interacts only weakly with the Fronted Argument factor in multiple questions- Compare this result with the one reported in Fanselow et al (2011), where it was found that, in German multiple questions, «acceptability is reduced when a[n object] wh- phrase crosses a wh- subject with which it agrees in animacy». The following pair illustrates the relevant contrast.

(15) a. Wen hat wer im Garten besucht? who.ACC has who.NOM in.the garden visited

[animate wh- object fronting]

b. Was hat wer im Garten besucht? what.ACC has who.NOM in.the garden visited

[inanimate wh- object fronting]

Participants were presented with a forced-choice test, where they had to indicate whether they accepted or rejected the items in question. Fanselow et al report that, while up to $97.5 \%$ of the participants accepted the examples with an inanimate object (15b), this proportion dropped to $70 \%$ in the case of examples with an animate object (15a). This difference is significant, but (as mentioned above) Experiments B and C failed to replicate it for Spanish. 


\section{Conclusions and outlook}

The main empirical result of this paper is that, contrary to what has been claimed in previous literature, Spanish does exhibit a Superiority effect, where multiple questions with a fronted wh- object are significantly less acceptable than their counterparts with a fronted wh- subject. Importantly, this penalty on object whfronting is replicated in single questions. This much suggests that the deviance of object wh- fronting in multiple questions is not a consequence of Superiority effect as traditionally understood (i.e., a violation of a locality principle like Relativized Minimality or Attract Closest), but rather a reflection of a more general ban on object wh- fronting. Moreover, Experiment B shows that relative clauses do not show any significant penalty on object relativization when compared to subject relativization. This implies that the penalty found in Experiments A and C doesn't range over A-bar movement constructions in general. At present, however, it is unclear to me how to integrate these asymmetries within the current theory of syntax. Similarly, Experiments B and C show that the animacy of the object is, at best, a very weak predictor of acceptability in both relative clauses and multiple questions. Compare this result with the one reported in Fanselow et al (2011), where object animacy does affect the overall acceptability of multiple questions. Again, it is not obvious how to account for the fact that Spanish and German differ in this respect.

More broadly, this article supports an approach to syntax in which the acceptability of a given A-bar construction doesn't depend on one single factor (e.g., an overarching locality condition), but on the interaction of a number of independent factors. As an anonymous reviewer helpfully mentions, it is arguable that subject-verb inversion (cf. Adli 2011) and specificity (cf. Frascarelli and JiménezFernández 2013) also play important roles, and as such merit being incorporated in future studies of this topic.

In his discussion of subject-verb inversion restrictions in Spanish, Goodall (2010) points out that experimental techniques (including both properly designed questionnaires and quantitative analysis of the results) «can give us more certainty about the status of data where there have been disputes or doubts, as well as more precision in dealing with subtle contrasts among sentences». Here, I hope to have shown that Goodall's comment also holds in the realm of Superiority effects -i.e., by carefully crafting the experiments and by gathering data from a large number of speakers, it is possible to detect data asymmetries that often escape introspective author judgments - Regrettably, though, the detection of an empirical effect doesn't necessarily lead us to a theoretical account of said effect, and as such I am forced to conclude this article with more open questions than there were at the beginning. 


\section{References}

Adli, Aria (2011). «A heuristic mathematical approach for modeling constraint cumulativity: contrastive focus in Spanish and Catalan». The Linguistic Review 28: 111-173.

Aoun, Joseph; Li, Audrey (2003). Essays on the derivational and representational nature of grammar. Cambridge, MA: MIT Press.

Baayen, Harald (2009). LanguageR: data sets and function from «Analyzing linguistic data: a practical introduction to statistics using R». [http://cran.r-project.org/web/ packages/languageR]

Baayen, Harald; Davidson, Doug; Bates, Douglas (2008). «Mixed-effects modeling with crossed random effects for subjects and items». Journal of Memory and Language 59: 390-412.

Baković, Eric (1998). «Optimality and inversion in Spanish». In: Barbosa, Pilar; Fox, Daniel; hagstrom, Paul; McGinis, Martha; Pesetsky, David (eds.). Is the best good enough? Optimality and competition in syntax. Cambridge, MA: MIT Press, pp. $35-58$.

Bates, Douglas; Maechler, Martin; Bolker, Ben (2009). lme4: linear mixed effects models using S4 classes. [http://cran.r-project.org/web/packages/lme4].

Chomsky, Noam (1995). The minimalist program. Cambridge, MA: MIT Press.

Chomsky, Noam (2005). «On phases». MIT, unpublished manuscript.

Clark, Herbert H (1973). «The language-as-fixed-effect fallacy: a critique of language statistics in psychological research». Journal of Verbal Learning and Verbal Behavior 12: 335-359.

Cuervo, María Cristina (2003). Datives at large. MIT, doctoral dissertation.

Fanselow, Gisbert (1997). «Minimal Link effects in German (and other languages)». Universität Potsdam, unpublished manuscript.

Fanselow, Gisbert (2004). «The MLC and derivational economy». In: Stepanov, Arthur; Fanselow, Gisbert; Vogel, Ralf (eds.), pp. 73-124.

Fanselow, Gisbert; Féry, Caroline (2008). «Missing Superiority effects: long movement in German (and other languages)». In: Witkos, Jacek; Fanselow, Gisbert (eds.). Elements of Slavic and Germanic grammars: a comparative view. Frankfurt: Peter Lang, pp. 67-87.

Fanselow, Gisbert; Schlesewsky, Matthias; Vogel, Ralf; Weskott, Thomas (2011). «Animacy effects of crossing wh- movement in German». Linguistics 49: 657-683.

Featherstone, Sam (2005). «Universals and grammaticality». Linguistics 43: 667-711.

Fiengo, Robert; Huang, James C.-T.; Lasnik, Howard; Reinhart, Tanya (1988). «The syntax of wh- in situ». In: Borer, Hagit (ed.). Proceedings of WCCFL 7. Stanford: CSLI, pp. 81-98.

Fitzpatrick, Justin (2002). «On minimalist approaches to the locality of movement». Linguistic Inquiry 33: 443-463.

Frascarelli, Mara; Jiménez-Fernández, Ángel (2013). «Fronting contrast at the interfaces. Handout», Cam Cos 2.

Goodall, Grant (2010). «Experimenting with wh- movement in Spanish». In: Arregi, Karlos; Fagyal, Zsuzsanna; Montrul, Silvina A.; Tremblay, Annie (eds.). Romance Linguistics 2008: Interactions in Romance. Amsterdam: John Benjamins, pp. 233-248. 
Haider, Hubert (2004). «The Superiority conspiracy». In: Stepanov, Arthur; Fanselow, Gisbert; Vogel, Ralf (eds.), pp. 147-175.

Jaeggli, Osvaldo (1982). Topics in Romance syntax. Dordrecht: Foris.

Müller, Gereon (2004). «Phase impenetrability and wh- intervention». In: Stepanov, Arthur; Fanselow, Gisbert; Vogel, Ralf (eds.), pp. 289-325.

Ordóñez, Francisco (1997). Word order and clause structure in Spanish and other Romance languages. CUNY Graduate Center, doctoral dissertation.

Pesetsky, David (1987). «Wh- in-situ: movement and unselective binding». In: Reuland, Eric; ter Meulen, Alice G.B. (eds.). The representation of (in)definiteness. Cambridge, MA: MIT Press, pp. 98-129.

Pesetsky, David (2000). Phrasal movement and its kin. Cambridge, MA: MIT Press.

Raaijmakers, Jeroen (2003). «A further look at the 'language-as-fixed-effect fallacy'». Canadian Journal of Experimental Psychology 57: 141-151.

Stepanov, Arthur; Fanselow, Gisbert; Vogel, Ralf (eds.). Minimal effects in syntax. Berlin: Mouton de Gruyter.

Strotzer, Judith-Reina (1976). Clitics in Spanish. UCLA, doctoral dissertation,

Suñer, Margarita (1988). «The role of agreement in clitic doubled constructions». Natural Language and Linguistic Theory 6: 391-434. 